\title{
Mindfulness and Its Relation to Academic Procrastination among University Students
}

\author{
Fatima Eltayeb \\ Faculty of Educational Sciences, Prince Sattam Bin Abdulaziz University, Saudi Arabia
}

Received November 29, 2020; Revised February 10, 2021; Accepted March 23, 2021

\section{Cite This Paper in the following Citation Styles}

(a): [1] Fatima Eltayeb , "Mindfulness and its Relation to Academic Procrastination among University Students," Universal Journal of Educational Research, Vol. 9, No. 5, pp. 917 - 927, 2021. DOI: 10.13189/ujer.2021.090504.

(b): Fatima Eltayeb (2021). Mindfulness and its Relation to Academic Procrastination among University Students. Universal Journal of Educational Research, 9(5), 917 - 927. DOI: 10.13189/ujer.2021.090504.

Copyright $(2021$ by authors, all rights reserved. Authors agree that this article remains permanently open access under the terms of the Creative Commons Attribution License 4.0 International License

\begin{abstract}
This study explored the level of mindfulness among Sattam Bin Abdulaziz University students and its relation to academic procrastination. The study was randomly chosen from different academic levels to be suitable for the sample of this study, where 1890 female students were chosen. A total of 206 students from science and arts sections participated in the study. The descriptive approach was used because it was more suitable for this study. For statistical analysis and conclusions, two measurement scales devised by the researcher were used: the Mindfulness Scale and the Academic Procrastination Scale. To find the suitability of those scales, honesty and stability factors were implemented on both. For data processing, SPSS statistical program was used to compute means, correlations, 1-taled and 2-tailed t-tests of students' scores on the two scales. Results revealed that students had a high level of both mindfulness and academic procrastination. A statistically significant inversely proportional relationship was found between mindfulness and academic procrastination at $(0,5)$ level. Furthermore, significant differences in mindfulness were found by study level in favor of the seventh level students. No statistically indicated significant differences in mindfulness and procrastination at $(0,5)$ level were found by specialization (science vs. arts). After the statistical results, the researcher recommended to have more concern about counseling programs which aim to develop mindfulness, to increase awareness, and also to pay attention to the educational situation. Moreover, to do tasks on time will help make a positive cooperation and build more confidence between students and teaching staff members. In addition, the researcher recommended implementing counseling programs to eliminate the feature of academic
\end{abstract}

procrastination among students. This study also recommended and emphasized the significance of improving E-learning and using new technology to make the educational process more attractive.

Keywords Mindfulness, Academic Procrastination, Procrastination

\section{Introduction}

University study is crucial for students because it outlines their future careers. Thus, it is imperative for students to be mindful and industrious. Excellence in study depends to a large extent on students' mindfulness and mental readiness. Learning requires mental alertness that includes the individual's awareness of his/her problems mainly and its effect on cognitive aspects so that the individual realizes the stimuli around $\mathrm{him} / \mathrm{her}$. Learning also requires non-routine practices and stimulating mental efforts, so attention is an essential process for gaining skills that focus students' attention on specific situations [1]. Mindfulness was found to be affected by the individual's expectations, motivation and ability to plan and achieve [2].

\section{Mindfulness}

Mindfulness means paying focused and purposeful attention to the learning situation. Ibn Al-Jawzia [3] identified the factors that were related to attentive learning. 
If every student is attentive and present in the mind, he/she will be more interactive and more responsive to what he/she hears, and if his/her mind is distracted and turned to other issues, the effect of learning will disappear. This is what applies to the state of mindfulness in academic achievement in our educational institutions at the present time. Mindfulness, as scholars have agreed, is a purely psychological concept through its focus on conscious attention - and on the individual's experience of life. According to Hasker [4], mindfulness refers to self-regulation of moment-by-moment attention, openness and awareness of experiences. Ismail [5] asserts that mindfulness is very significant in our daily life. It is an important element of mental health. It establishes a connection between mental health, psychological stability, self-esteem and life satisfaction.

Studies have proven that mindfulness enhances one's attention, self-confidence and ability to cope with pressures. Mindfulness was also found to increase one's feeling of happiness. Nicola and Andreadel, [6] suggested that Greater Mindfulness is Linked to Less Procrastination. Al-Bediwi [7] asserts that we can change our lives by paying more attention and practicing more control in the situations we experience, as attention promotes our performance. Viewing mindfulness as a life style, Shoaib [8] states that a mindful student can sort received information and treat it by conscious interpretation.

Recently, there has been a call in educational institutes for programs to enhance students' mindfulness. This aims to improve students' life skills, enhance emotional balance, eliminate tension and support classroom environment [9]. Among the benefits of mindfulness, as supported by Rieken, Schar and Sheppard [10], is enhancing cognitive flexibility. As reported in the study by Al-Waleed [11], mindfulness increases one's happiness, enhances his/her ability to solve problems and gives him/her more stability.

Several studies supported the importance of mindfulness. Howell, [12] examined the relations among mindfulness, achievement-related self-regulation, and achievement emotions. Results revealed that mindfulness relates to achievement and self-regulation and enhances well-being.

The researcher believes that mindfulness enhances conscious attention in learning and life situations and makes individuals responsible for their actions. By mindfulness, one can become proactive rather than reactive since mindful individuals are more able to consciously control their behavior. The mindful student can notice connections between study courses and this way s/he can use one course to understand another course. Mindfulness can also enhance creativity and achievement. Mental ability is at the utmost level during post-secondary education and it can be a national resource if it is exploited.

Students' mindfulness captured the researchers' interest because of its importance in the learning/teaching process.
Mohammed [13] explored the relationship between psychological flow, academic procrastination and mindfulness. A sample of 70 female students participated in the study. Results revealed that students had high levels of psychological flow and mindfulness and a moderate level of academic procrastination. Al-Nawab \& Mohamed [14] researched life orientation and its relationship to spiritual intelligence and mindfulness of 318 secondary school students. Students were found to have high levels of life orientation, spiritual intelligence and mindfulness. A significant positive correlation was found between the three variables. Mindfulness explained $10.4 \%$ of the total variance in life orientation.

In the study conducted by Rabie [15], the relationship between emotional intelligence and mindfulness was examined. The sample consisted of 420 male and female students from Yarmouk University. Participants were found to have an average level of mindfulness but a high level of emotional intelligence. Significant gender differences in mindfulness were found in favor of male students. Also significant differences in mindfulness by study level were found between second year and fourth year students in favor of second year Students. No significant differences in mindfulness by specialization were found.

Abdulhamid [16] investigated the relationship between mindfulness and academic emotional regulation of 200 university students. Results revealed a high level of mindfulness among students. A positive correlation was found between mindfulness and academic emotional regulation. Furthermore, mindfulness was found to predict academic regulation. Salahat and Al-Zaghoul [17] investigated the predictive power of big personality factors in mindfulness and whether the level of mindfulness varied by gender or academic specialization. The sample consisted of (760) male and female students. Results showed that students' mindfulness was moderate in general and in all dimensions of mindfulness except for an observation that was high. Furthermore, results showed significant gender differences in observation in favor of females. Significant differences in two dimensions of mindfulness (acting with awareness and non-judging) were found by college in favor of human science majors.

Al-Shalawi [18] explored mindfulness and its relation to self-efficacy among 154 College of Education students at AL-Dawadmi, KSA. The results of the study showed that students had high levels of mindfulness and self-efficacy. Moreover, there was a statistically significant correlation between mindfulness and self-efficacy. Al-Walid [19] identified the level of mindfulness among 275 students at King Khaled University, KSA. Students proved to have a moderate level of mindfulness. Results proved also that happiness could be predicted by mindfulness for female students.

Sennary [20] sought to identify the psychological resilience of 223 College of Education students and its 
relation to their mindfulness. Students were found to have low levels of psychological resilience, but above average levels of mindfulness. A significant correlation was found between psychological resilience and mindfulness. In addition, mindfulness contributed to the predictability of psychological resilience among the study sample. Al-Saqa [21] explored mindfulness among 160 students of the Girls' College at Ain Shams University and its relation to anger. A strong negative relationship was found between anger and mindfulness.

Abdullah [22] explored differences in university students' mindfulness by gender and specialization. The sample consisted of 500 students. Overall, students had a high level of mindfulness. Significant differences were found in favor of male students. No significant differences were found by specialization. The researcher concluded that mindful students were aware of their environment and what went on around. They showed stronger attention and desire to fulfill tasks. They also had stronger memory and higher creativity. In the study by Semple and Miller [23], mindfulness was found to reduce academic pressures and test anxiety. It enhanced academic self-efficacy and academic performance.

The previous studies revealed the positive effect of mindfulness on the learning process as a whole and on such individual variables as performance, behavior and psychological resilience.

\section{Procrastination}

Performing tasks and assignments is common among university students. It is defined by Johnson, Green, and Kluere [24] as delaying work that needs to be accomplished for a later time. When repeated, procrastination becomes a problem for students, as it has adverse effects on them and on the society. Procrastination can cause self-blame, regret, weak academic accomplishment and loss of opportunities [25].

Ozer and Ferrair, [26] contend that the tendency to delay tasks is a personality trait rather than ineffective time management. It is a complex phenomenon and it has several types [27]. In arousal procrastination, the individual procrastinates for amusement and suspense. In avoidant procrastination, the individual procrastinates to protect themselves or out of fear, which are all behavioral procrastination. Finally, there is decisional procrastination where the individual delays decisions.

Valdez [28] identifies three patterns of unconcerned students. They just seek success and appeal for help in the last moments. They procrastinate too much. Target-oriented and passionate students, on the other hand, seldom procrastinate. Research documented weak achievement among students with high procrastination [29]. Other negative effects of procrastination include hatred for study, low self-esteem, and fear and anxiety of failure [30]. Procrastination can result from several factors. According to Noran and Abu Ghazal [29], it could be due to weak time management, the inability to concentrate, failure-related fear and anxiety and low level of mindfulness.

Explanations of procrastination varied from a psychological school to another. Behaviourism viewed procrastination as an acquired habit that stems from the individual's preference for activities with immediate awards. Psychoanalysis attributed procrastination to over-tolerance for parents. Proponents of the cognitive school referred to attribution and self-handicapping as causes of procrastination. Not all procrastinating behaviors are negative. Whether procrastination is negative or positive depends on personality traits. There are passive procrastinators who delay tasks to the last moment because of their inability to make decisions. There are also active procrastinators who make intended procrastination decisions and use high motivation under time pressure and can complete tasks in specified times [31].

Al-Zoubi [30] explored the relationship between academic procrastination and both self-efficacy and anxiety about the future using a sample consisting of 300 students from Damascus University. More than $75 \%$ of the participants were found to procrastinate. A positive relationship was reported between academic procrastination and academic self-efficacy. However, no correlation was found between academic procrastination and anxiety about the future. Aboud [32] examined the relationship between life stressors and procrastination using a sample of 124 undergraduate students from Ajloun University. Results revealed a significant correlation between life stressors and academic procrastination. Significant differences were found in the strength of the relationship between life stressors and academic procrastination in favor of male students. No Significant differences were found in the strength of the relationship between life stressors and academic procrastination by academic level.

Experimenting on 202 undergraduate university students, Al-Janadi and Amer [33] investigated the relationship between academic procrastination and parental socialization styles and classroom environment. Results revealed a negative relationship between academic procrastination and encouragement and the total score on the classroom environment scale. Significant differences were found in procrastination between second and seventh level students.

Shabib [34] investigated the frequency of academic procrastination and its causes from the perspective of undergraduate students. The sample consisted of 496 undergraduate students (225 males, 271 females), from all colleges of Tishreen University. Results showed that $14.5 \%$ of participants exhibited a high level, $65.5 \%$ exhibited an average level, and $20 \%$ exhibited a low level 
of procrastination. Procrastination among males was higher than that among females. Causes of procrastination included aversive tasks, fear of failure, instructor style, risk taking, classmate pressure, and resisting discipline control. Significant differences were found by academic level. Procrastination among first year students was higher than among fourth year students. Procrastination was higher among arts students than among science students.

Abu-Ghazal [29] explored the prevalence of academic procrastination and its causes from the perspective of undergraduate students. The sample consisted of 751 undergraduate students (222 males, 529 females), from all colleges of Yarmouk University. Results showed that $21.6 \%$ of participants exhibited a high level of procrastination, $60.3 \%$ exhibited an average level, and $18.1 \%$ exhibited a low level. Procrastination among fourth year students was higher than among students in all other years. No significant differences were found gender or specialization.

Abdulrahim and Ali [35] studied the relationship between academic procrastination and time management among College of Education students $(\mathrm{N}=368)$. Students were found to have very low levels of academic procrastination. However, their time management was weak. The relationship between academic procrastination and time management was weak.

Li Cao [36] compared academic procrastination and achievement motivation of undergraduate $(\mathrm{N}=66)$ and postgraduate students $(\mathrm{N}=68)$. Undergraduate students were found to procrastinate more than postgraduate students.

Hussain and Sultan [37] explored the psychological causes of academic procrastination and the effect of these cusses on the learning of 500 university students. Results revealed a negative impact of procrastination on learning and achievement motivation. Balkis and Duru [38] investigated the prevalence of academic procrastination among student teachers and its relation to demographic variables and individual preferences. A total of 580 College of Education students participated in the study. Results revealed that $23 \%$ of the participants exhibited a high level and $27 \%$ exhibited an average level of procrastination. In general, procrastination was found to decrease with age.

Onwuegbuzie [39] investigated the prevalence of academic procrastination among 784 Turkish students and its causes in the light of gender and study level. Results showed that $25 \%$ of the participants reported that they repeatedly procrastinated. No significant correlation was found between study level and academic procrastination. The frequency of procrastination among students was found to range from $40 \%$ to $60 \%$. Ghuneim [40] studies academic procrastination and its relation to some personality variables among College of Education Kuwaiti students $(\mathrm{N}=324)$. A statistically significant relationship was reported between academic procrastination and the
GPA. Age correlated with academic procrastination.

The previously surveyed studies reveal that academic procrastination is common among university students. It was revealed that academic procrastination correlate with several factors, e.g., time management, life pressures and personality traits. What is new about the present study is that it related procrastination to mindfulness. Procrastination proved to have negative effects on students' performance. It therefore needs to be further examined to reach a deeper understanding of its nature. Such an investigation can inform decision makers and program developers about how to eliminate procrastination.

Wang and Englander [41] and Ozer [42] assert that academic procrastination is an educational and psychological problem that got worse with technological development. It causes psychological disability and wastes time [30]. This means that university students who procrastinate may have low mindfulness, which affects their completion of academic tasks. Undoubtedly, procrastination has a negative impact on study and deters students from achieving their goals. To the best of the researcher's knowledge, no previous study explored the nature of procrastination and its relation to mindfulness. The present study would hopefully identify this relationship.

\section{Statement of the Problem}

Attention is a prerequisite for learning to take place. It enables students to select suitable stimuli from the external environment. Individuals often pay attention to new stimuli. Mindful students are fully aware of their environment. Research has proved that mindful students show greater attention and desire to perform tasks [18]. The researcher observed in her classrooms that some students took notes out of a fear to forget. They also complained about their inability to be attentive during lectures, which affects their achievement negatively. I also observed a high level of procrastination among students. Many of them used to hand assignments after deadlines. Accordingly, this study aimed to explore the relationship between mindfulness and academic procrastination. More specifically, the study addressed the following questions:

1. What is the level of mental alertness among students of Prince Sattam University?

2. What is the level of academic procrastination among students of Prince Sattam University?

3. Does the level of mental alertness of Prince Sattam University students differ according to the specialization?

4. Does the level of mental alertness of Prince Sattam University students differ according to the student's class level? 
5. Does the level of academic procrastination of Prince Sattam University students differ according to the specialization?

6. Does the academic procrastination level of Prince Sattam University female students differ according to the student's class level?

7. Is there a relationship between mindfulness and academic procrastination among students of Prince Sattam University?

\section{Aims of the Study}

This study aimed to identify:

1. The level of mindfulness among Prince Sattam University students.

2. The level of procrastination among Prince Sattam University students.

3. Differences in mindfulness by specialization and study level.

4. Differences in procrastination by specialization and study level.

\section{Definition of Terms}

\section{Mindfulness}

Conceptually, mindfulness refers to purposeful conscious attention, management of ideas and awareness of the learning situation. Operationally, it refers to the score obtained by the student on the researcher-developed mindfulness scale.

\section{Procrastination}

Conceptually, procrastination refers to the tendency to delay academic tasks or not to complete them in specified time, which causes tension and stress [29] [30]. Operationally, it refers to the score obtained by the student on the researcher-developed procrastination scale.

\section{The Limits of the Study}

Human limits: This study was limited to 206 female students registered in the bachelor's stage at Prince Sattam bin Abdulaziz University.

Time limits: The research was conducted during the second semester of the 2019-2020 academic year.

Spatial boundaries: This research was conducted at
Al-Kharj Governorate in the Kingdom of Saudi Arabia. Method

The researcher used the descriptive method to explore the relationship between mindfulness and academic procrastination and differences in the two variables by students' specialization and study level.

\section{Method}

The researcher used the descriptive method to explore the relationship between mindfulness and academic procrastination, and also the differences in the two variables; students' specialization and study level.

\section{Study population}

The population of the study was all female students at Prince Sattam Bin Abdulaziz University in the academic year 2019-2020. 1890 students were chosen, Of that population, 206 students (105 science students and 101 art students) were randomly selected to participate in the study. Of those 206 students, 106 were from the first level and 100 were from the seventh level.

Table distribution of study sample.

\begin{tabular}{|c|c|c|}
\hline specialization & Number & Percentage \\
\hline Scientific & 105 & $51 \%$ \\
\hline Litrary & 101 & $49 \%$ \\
\hline Total & 206 & $100 \%$ \\
\hline
\end{tabular}

\section{Instruments}

The Mindfulness Scale: After surveying related literature, the researcher developed a scale to assess mindfulness. The preliminary version of the scale consisted of 5-point Likert scale of 30 items. The preliminary version content validated by The tool was presented to (9) experts, Dr in educational sciences, who work in university education

Based on the feedback provided by the specialists, some items were modified. The researcher then pilot-tested the scale on 30 students rather than main study participants.

The internal consistency of the scale was then checked by computing correlations among items and the total score of the scale. The correlations of two items (2 and 5) were negative and therefore they were excluded from the scale. Correlations of the remaining 28 items ranged between 0.22 and 0.55 , which were all acceptable. These correlations are listed in table 1. 
Table 1. The internal consistency of the mindfulness scale

\begin{tabular}{|c|c|c|c|c|c|c|c|c|c|}
\hline Item & $\begin{array}{c}\text { Correlation } \\
\text { coefficient }\end{array}$ & Item & $\begin{array}{c}\text { Correlation } \\
\text { coefficient }\end{array}$ & Item & $\begin{array}{c}\text { Correlation } \\
\text { coefficient }\end{array}$ & Item & $\begin{array}{c}\text { Correlation } \\
\text { coefficient }\end{array}$ & Item & $\begin{array}{c}\text { Correlation } \\
\text { coefficient }\end{array}$ \\
\hline 1 & .550 & 7 & .435 & 13 & .406 & 19 & .615 & 25 & .461 \\
\hline 2 &. .023 & 8 & .410 & 14 & 246. & 20 & .302 & 26 & .305 \\
\hline 3 & .427 & 9 & .432 & 15 & .265 & 21 & .238 & 27 & .373 \\
\hline 4 & .421 & 10 & .278 & 16 & .235 & 22 & .346 & 28 & .299 \\
\hline 5 &. .072 & 11 & .283 & 17 & .422 & 23 & .281 & 29 & .202 \\
\hline 6 & .264 & 12 & .505 & 18 & .271 & 24 & .284 & 30 & .252 \\
\hline
\end{tabular}

Table 2. Different types of validity and reliability of the mindfulness scale

\begin{tabular}{|c|c|c|c|c|c|}
\hline Variable & Deleted items & Alpha reliability coefficient & Intrinsic validity & \multicolumn{2}{|c|}{ Split-half reliability } \\
\hline & & & & Spearman-Brown & Guttmann \\
\hline Mindfulness & 2,5 & .812 & .901 & .814 & .809 \\
\hline
\end{tabular}

Table 3. The internal consistency of the procrastination scale

\begin{tabular}{|c|c|c|c|c|c|c|c|}
\hline Item & Correlation & Item & Correlation & Item & Correlation & Item & Correlation \\
\hline 1 & .390 & 7 & .256 & 13 & .290 & 19 & .215 \\
\hline 2 & .443 & 8 & .573 & 14 & .405 & 20 & .256 \\
\hline 3 & .265 & 9 & .457 & 15 & .409 & 21 & .380 \\
\hline 4 & .455 & 10 & .453 & 16 & .365 & 22 & .317 \\
\hline 5 & .134 & 11 & .475 & 17 & .290 & 23 & .391 \\
\hline 6 & .470 & 12 & .410 & 18 & .452 & & \\
\hline
\end{tabular}

Table 4. Different types of validity and reliability of the procrastination scale

\begin{tabular}{|c|c|c|c|c|c|}
\hline Variable & Deleted items & $\begin{array}{c}\text { Alpha reliability } \\
\text { coefficient }\end{array}$ & $\begin{array}{c}\text { Intrinsic } \\
\text { validity }\end{array}$ & & Split-half reliability \\
\hline & & & & Spearman-Brown & Guttmann \\
\hline Procrastination & 5 & .818 & .904 & .727 \\
\hline
\end{tabular}

The intrinsic validity of the mindfulness scale was also established. The scale yielded a reliability coefficient of 0.812 and thus the square root was 0.901 , which is a high value. This indicates that the scale was intrinsically valid and could be used in the present study to collect valid information about students' mindfulness.

The reliability of the mindfulness scale was established by alpha Cronbach and split-half methods. The obtained reliability coefficients obtained from the two methods were 0.812 and 0.814 (Spearman-Brown) respectively. These are high values, hence indicating that the scale was quite reliable. Table 2 shows validity and reliability coefficients of the mindfulness scale.

Thus, the final version of the mindfulness scale consisted of 28 items of the 5-point Likert scale type. Items with negative wording were reversely coded.

\section{The Procrastination Scale}

Based on a survey of related literature [29]; [38]; [44]; [43] the researcher developed a scale to assess students' academic procrastination. Initially, the scale had 23 items measuring delayed completion of tasks and assignments. The scale content was validated by nine specialists. Slight modifications were made based on the specialists' comments. The scale was then test-piloted on 30 students rather than all students in the main sample.

The internal consistency of the procrastination scale was checked by computing correlations between items and the total score. The correlation of item 5 was weak and thus it was excluded. Correlations of the other items ranged from 0.202 to 0.550 , which were all acceptable values.

The intrinsic validity of the mindfulness scale was also established. The scale yielded a reliability coefficient of 0.818 and thus the square root was 0.904 , which is a high value. This indicates that the scale was intrinsically valid and could be used in the present study to collect valid information about students' academic procrastination.

The reliability of the procrastination scale was established by alpha Cronbach and split-half methods. The obtained reliability coefficients obtained from the two methods were 0.818 and 0.727 (Spearman-Brown) respectively. These are high values, hence indicating that the scale was quite reliable. Table 4 shows validity and reliability coefficients of the procrastination scale.

Thus, the final version of the mindfulness scale consisted of 22 items of the 5-point Likert scale type. Items with negative wording were reverse coded. 


\section{Results}

\section{The level of mindfulness among students}

Means, standard deviations and 1-taled t-test were computed to identify the level of mindfulness among students. These data are shown in table 5 .

It can be observed from table 5 that the difference between arithmetic and hypothetical means was statistically significant. The t-value was 26.74 , which is significant at the 0.01 level. The difference was in favor of the arithmetic mean, hence indicating high significance. That is, students' mindfulness was significantly high.

\section{The level of procrastination among students}

Means, standard deviations and 1-taled t-test were computed to identify the level of procrastination among students. These data are shown in table 5 .

It is clear from table 6 that the difference between arithmetic and hypothetical means was statistically significant. The t-value was 2.35 , which is significant at the 0.05 level. The difference was in favor of the arithmetic mean, hence indicating high significance. That is, students' mindfulness Vs. procrastination.

\section{The relationship between mindfulness and procrastination}

To identify the relationship between mindfulness and procrastination, Pearson correlation was computed. The results of this statistic are listed in table 7.
Data in table 7 reveals that the pearson correlation coefficient was statistically significant $(\mathrm{r}=-.472, \mathrm{p}=0.01)$. Therefore, it could be stated that there was a statistically significant negative correlation between mindfulness and academic procrastination. That is, the higher the level of students' mindfulness, the less their level of procrastination.

\section{Differences in mindfulness by specialization}

To identify differences between science and arts students in mindfulness, the 2-tailed t-test was computed. These results are presented in table 8 .

From table 8 , it could be observed that the difference between the two means was not significant $(\mathrm{t}=0.517$, $\mathrm{p}=0.606$ ). This indicates that the difference between science and arts students in mindfulness was not significant. That is both groups had similar levels of mindfulness.

\section{Differences in academic procrastination by specialization}

To identify differences between science and arts students in procrastination, 2-tailed t-test was computed. These results are presented in table 9.

From table 9, it can be observed that the difference between the two means was not significant $(\mathrm{t}=0.513$, $\mathrm{p}=0.609$ ). This indicates that the difference between science and arts students in procrastination was not significant. That is both groups had similar levels of procrastination.

Table 5. One-tailed t-test for the general level of students' mindfulness

\begin{tabular}{|c|c|c|c|c|c|c|c|c|}
\hline Variable & Sample size & No. of items & Criterion mean & M & SD & df & t-value & Sig. \\
\hline Mindfulness & 206 & 28 & 84 & 105.77 & 11.68 & 205 & 26.74 & .000 \\
\hline
\end{tabular}

Table 6. One-tailed t-test for the general level of students' academic procrastination

\begin{tabular}{|c|c|c|c|c|c|c|c|c|}
\hline Variable & Sample size & No. of items & Criterion mean & M & SD & df & t-value & Sig. \\
\hline Procrastination & 206 & 22 & 66 & 68.02 & 12.34 & 205 & 2.35 & .020 \\
\hline
\end{tabular}

Table 7. The relationship between mindfulness and procrastination

\begin{tabular}{|c|c|c|c|}
\hline Variables & Sample size & Pearson correlation & Sig. \\
\hline Mindfulness & 206 & $-.472(* *)$ & $\mathbf{0 . 0 0 0}$ \\
\hline Procrastination & & & \\
\hline
\end{tabular}

Table 8. Two-tailed t-test for differences between science and arts students in mindfulness

\begin{tabular}{|c|c|c|c|c|c|c|c|}
\hline Variable & Group & Sample size & M & SD & df & t-value & Sig. \\
\hline \multirow{2}{*}{ Mindfulness } & Science & 105 & 106.19 & 11.49 & \multirow{2}{*}{204} & \multirow{2}{*}{.517} & \multirow{2}{*}{.606} \\
\cline { 2 - 8 } & Arts & 101 & 105.34 & 11.92 & & & \\
\hline
\end{tabular}

Table 9. Two-tailed t-test for differences between science and arts students in procrastination

\begin{tabular}{|c|c|c|c|c|c|c|c|}
\hline Variable & Group & Sample size & M & SD & df & t-value & Sig. \\
\hline \multirow{2}{*}{ Procrastination } & Science & 105 & 68.56 & 12.84 & \multirow{2}{*}{204} & & \multirow{2}{*}{-.513} \\
\cline { 2 - 6 } & Arts & 101 & 67.54 & 11.72 & & & .609 \\
\hline
\end{tabular}


Table 10. Two-tailed t-test for differences in mindfulness by study level

\begin{tabular}{|c|c|c|c|c|c|c|c|}
\hline Variable & Group & Sample size & M & SD & df & t-value & Sig. \\
\hline \multirow{2}{*}{ Mindfulness } & Level 1 & 106 & 104.00 & 11.97 & \multirow{2}{*}{204} & \multirow{2}{*}{-2.14} & \multirow{2}{*}{.033} \\
\hline & Level 7 & 100 & 107.47 & 11.19 & & & \\
\hline
\end{tabular}

Table 11. Two-tailed t-test for differences in procrastination by study level

\begin{tabular}{|c|c|c|c|c|c|c|c|}
\hline Variable & Group & Sample size & M & SD & df & t-value & Sig. \\
\hline \multirow{2}{*}{ Procrastination } & Level 1 & 106 & 69.83 & 12.78 & \multirow{2}{*}{204} & & 2.54 \\
\cline { 2 - 8 } & Level 7 & 100 & 66.28 & 11.71 & & & .012 \\
\hline
\end{tabular}

\section{Differences in mindfulness by study level}

To identify differences in students' mindfulness by study level, the 2-tailed t-test was computed. These results are presented in table 10.

As listed in the table 10, it could be seen that the difference between the two means was significant $(\mathrm{t}=2.14$, $\mathrm{p}=0.033$ ) in favor of the seventh level students. This indicates that the seventh level students had a significantly higher level of mindfulness than the first level students.

\section{Differences in procrastination by study level}

To identify differences in students' procrastination by study level, the 2-tailed t-test was computed. These results are presented in table 11 .

As listed in the table 11, it can be seen that the difference between the two means was significant $(\mathrm{t}=2.54$, $\mathrm{p}=0.012$ ) in favor of the first level students. This indicates that the first level students had a significantly higher level of academic procrastination than the seventh level students.

\section{Discussion}

Results revealed that students had a high level of mindfulness. This finding concurs with the studies conducted by Abdulhamid [16], Al-Shalawi [18] and Abdullah [45] where university students were reported to have a high level of mindfulness. However, this finding is inconsistent with the studies conducted by Sennary [20], and Walid [11] where students were reported to have a moderate level of mindfulness. This finding seems logical given that university students are aware that they need to be attentive to benefit from all learning situations in order to have a place in the labour market when they graduate. In this respect, Albrecht and Cohen [46] assert that mindfulness enables the individual to be aware of the reality and understand themselves. Hassed [47] suggests that mindfulness enhances mental health and promotes communication and sympathy. Empirically, in Howell \& Buro [48] study mindfulness correlated with achievement, self-regulation and welfare.

Participants in the present study were found to have a high level of academic procrastination. This finding is consistent with Al-Zoubi [29], Onwuegbuzie [39] and
Hussain and Sultan [37]. It partially concurs with Balkis and Duru [44] and Ozer, Demur and Ferrair [42]. In the study by Abu-Ghazal [29] for instance, $82 \%$ of the participants had moderate to high academic procrastination. This is a serious issue that needs to be addressed, as academic procrastination has negative effects on learning and achievement.

The high level of academic procrastination can be due to the numerous distractors in today's technological age. Television channels have become so attractive and smart phones with their various applications have become accessible to most people. There are also social media that have become an integral part of everyone's life. These can take much of students' time and distract them from their study. They can also interfere with students' completion of their academic tasks and assignments. What asserts the negative interference of such technological products is that students use smartphones during classes. Even when forced not to use smartphones during classes, students can sit in classes distant-minded. In this respect, recent research reported the prevalence of excessive use or addiction of smartphones among university students.

The data also revealed a significant negative relationship between mindfulness and academic procrastination. No other research, to the best of the researcher's knowledge, investigated this relationship. However, academic procrastination correlated negatively with other variables in previous studies, e.g., self-efficacy, academic performance [43], time management and parental socialization techniques. This negative relationship means that the more the students are mindful, the less they academically procrastinate. This seems reasonable because mindful students are always aware of what is required of them and thus tend to complete tasks in the specified time.

Specialization had no effects on mindfulness in the present study. This finding is in line with the study conducted by Abdullah [45] where no significant differences in mindfulness were found by specialization (science vs. arts). One can contend therefore that mindfulness is an individual characteristic that is not affected by type of study. Similarly, specialization had no effects on academic procrastination. This is in line with the results reached by Al-Zoghbi [30] and Abu-Ghazal [29]. This indicates that academic procrastination is a 
common issue affecting students from all specializations.

Unlike specialization, study level proved to affect mindfulness; Seventh level students were more mindful than first level students. That is, older students were more mindful than younger students. This finding is inconsistent with the study conducted by Rabee [15] where second level students were more mindful than fourth level students. A possible explanation for this finding is that seventh level students are aware of the fact that they are about to graduate and thus focus more on their studies in order to find a place in the labour market. They are more mature and more responsible. They may have learned to attend learning situations from previous experiences. Besides, they can have more emotional control than younger students, which makes them more apt to manage their behavior.

Study level also proved to affect academic procrastination. But unlike the case with mindfulness, academic procrastination was found to be higher in younger students. First level students procrastinated much more than did the seventh level students. This finding concurs with the studies by Al-Janadi and Amer [33] and Li Cao [36]. However, it is inconsistent with the study by Shabib [34] where no significant differences in academic procrastination were found by study level. This finding can be explained in terms of maturation as the case with mindfulness. More mature students are more serious about their study. Younger students can be more affected by distractors than older students. Being aware that they are close to professional life, older students drive distractors away and take their study seriously.

\section{Conclusions}

Progress on the level of Female academic procrastination may be attributed to students due to their ability to focus on academic tasks and their personal interest in academic excellence. This result can also be attributed to the type of courses and the tendencies of the female students towards them, which affect academic procrastination, besides the great influence of the university teaching method.

\section{Recommendations}

Based on results, the following recommendations are offered:

1. Training students through specially designed programs to enhance their attention and do tasks in due times.

2. Executing counselling programs to eliminate academic procrastination.

3. Integrating e-learning and employing recent technology to increase the attraction of the educational process.

\section{Suggestions for Further Research}

1. Exploring the relationship between mindfulness and other variables, e.g., parental education and academic achievement.

2. Exploring the relationship between mindfulness and such psychological variables as big personality factors.

3. Exploring the effectiveness of counselling programs in enhancing mindfulness and eliminating academic procrastination.

\section{Acknowledgement}

This project was supported by the Deanship of Scientific Research at Prince Sattam Bin Abdulaziz University under the research project \#2019-02-10377\#.

\section{REFERENCES}

[1] Al-Assemi, Riyadh. (2012). Mindfulness and mental health. Resalat Al-Khalij, 10.

[2] Altre, S. (2012). Information, The Foundation of business New Jersey; Prentice Hall Publishers.

[3] Ibn Al-Jawzia, Abdulrahman bin Hassan Al-Timi. (1977). Remembrance in preaching, Damascus, the Islamic Library.

[4] Hasker, S.M. (2010). Evaluation of mindfulness acceptance commitment (mas) approach for enhancing athletic performance. Unpublished Ph.D Dissertation, Indiana University of Pennsylvania

[5] Ismail, Hala Khairy. (2017). Psychological flexibility and its relationship to mental alertness among students of the College of Education, Journal of Psychological Counseling, 5 (1).

[6] Schutte, N. S., \& Bolger, A. D. (2020). Greater Mindfulness is Linked to Less Procrastination. International Journal of Applied Positive Psychology, 5(1-2), 1-12. doi:10.1007/s41 042-019-00025-4

[7] Al-Bediwi, Zainab Saad. (2018). Predicting moral thinking from mental alertness and psychological reassurance among female students of the Faculty of Human Sciences in Al-Dahaqia, Journal of the College of Education.

[8] Shoaib, A. (2020). Mindfulness, psychological resilience and emotional intelligence as predictors of social emotional learning among a sample of student teachers. International Journal of Research in Educational Sciences. 3(2), 65-104.

[9] Arthuron, K. (2015). Teaching mindfulness to year sevens as part of health and Personal development. Australian Journal of Teacher Education, 40(5), 27-40.

[10] Rieken, B., Schar, M. \&Sheppard, S. (2016). Trait mindfulness in an engineering classroom: An exploration of the relationship between mindfulness, academic skills, and professional skills. IEEE Frontiers in Education Conference 
(FIE). doi:10.1109/FIE.2016.7757464

[11] Al-Walid, Ali Mohammed. (2017). Mindfulness and its relation to well-being of King Khaled University students. King Khaled University Journal, 28.

[12] Howell, A. J. \& Buro, K. (2011). Relations among mindfulness, achievement-related self-regulation, and achievement emotions. Journal of Happiness Studies: An Interdisciplinary Forum on Subjective Well-Being, 12(6), 1007-1022. https://doi.org/10.1007/s10902-010-9241-7

[13] Muhammad, Asma Abdo. (2019). Psychological flow and its relationship to academic lag and mental alertness, at the College of Education in Wadi, Arab Childhood Journal, p 4

[14] Al-Nawab, Naji Mahmoud \& Mohamed, Iyad Hashem. Study habits and motivation towards achievement and their relationship to academic lag of university students. Diyala University - Iraq

[15] Rabie, Faisal. (2019). Emotional Intelligence and its Relation to Mindfulness among Yarmouk University Students, The Jordanian Journal, 15 (1).

[16] Abdulhamid, Heba Jaber. (2018). Mindfulness and its relation to academic emotional regulation among university students. Journal of Psychological Counseling, 56.

[17] Salahat, Mohammed Ali \& Al-Zaghloul, Rafea Oqail. (2018). The predictive power of the big personality factors and their relation to mindfulness. Journal of Al-Quds Open University, 9(25), 21-38.

[18] Al-Shalawi, Ali Mohammed. (2018). Mindfulness and its relationship to self- efficacy among a sample of faculty of education students at Al-Dawadmi. Journal of Scientific Research in Education, 19, 2-24.

[19] Al-Walid, Ali bin Muhammad. (2017). Mental alertness and its relationship to psychological happiness among students of King Khalid University. King Khalid University Journal, 28

[20] Sennary, Hala Khair. (2017). Psychological resilience of college of education students and its relation to their mindfulness: A predictive study. Journal of Psychological Counseling, 50(1), 287-335

[21] Al-Saqa, Warda Othman Arafa. (2016). The relationship between mindfulness and anger management. Journal of Scientific Research in Education, 17, 626-649.

[22] Abdullah, Ahlam Mahdi. (2013). Mindfulness of university students. Alustath, 10205(205).

[23] Semple, R.J., Reid, E.\& Miller, 1. (2005). Training anxiety with Mindfulness: An openmindfulness Training for anxiety children. Journal of cognitive Psychotherapy, 19(4), 379-92. doi./10.189/jcop-2005.

[24] Johnson, E., Green, K. \& Kluere, R. (2000). Psychometric characteristics of revised procrastination inventory. Research in Higher Education,41(2), 267-279.

[25] Burka, J \& Yuen. (1983) procrastination why you do it, what to do abut it, New York Addison Wesley.

[26] Ozer. B.U. \& Ferrari, J,R (2011) Gender Orientation and academic procrastination Exploring Turkish high school students Individual Differences Research , 9 (1).
[27] Sahloul, Walid. (2014). Academic procrastination and metacognitive beliefs about academic procrastination and academic achievement - Journal of the Zagazig College of Education, 84

[28] Valdes. (2006) Math Study Skill .12 steps to success in math Retrieved November

[29] Abu-Ghazal, Muawia. Academic procrastination: prevalence and causes from the point of view of undergraduate students. The Jordanian Journal of Educational Sciences, 8(2), 131-149.

[30] Al-Zoubi, Ahmed Mohammed. (2017). Academic procrastination and its relationship to both self-efficacy and future anxiety I have a sample of Damascus University students. Damascus Magazine, 3 (1)

[31] Chu, A. \& Choi, J. (2005). Rethinking procrastination: positive effects of behavior on attitudes and performance. The Journal of Social Psychology 14,254-264.

[32] Aboud, Mohammed. (2012). The relationship between life stressors and academic procrastination among Ajloun University students. Al-Najah University Journal (Human Sciences), 30(3), 642-662.

[33] Al-Janadi, Lina Ahmed \& Amer, Ibtsam Mahmoud. (2015). Procrastination and its relation to treatment techniques and classroom environment. Journal of Benha Faculty of Education, 35.

[34] Shabib, Hana Saleh. (2015). Psychometric Properties of the Academic Procrastination Scale. Master Thesis, Damascus Syria.

[35] Abdulrahim, Saleh \& Ali, Saleh. (2013). Procrastination and its relation to time management among college of education students. Journal of Arab studies in education and Psychology, 3892), 32-46.

[36] Li Cao, (2012). Difference in procrastination and motivation undergraduate and graduate students. Journal of Scholarship of Teaching and learning, 12(2), 39-64.

[37] Hussain, I. \& Sultan, S. (2010). Analysis of procrastination among university students. Procedia: Social and Behavioral Sciences, 5, 1897-1904. doi:10.1016/j.sbspro.2010.07.385

[38] Balkis, M. \& Duru, E. (2009). Prevalence of procrastination behavior among pre-service teachers and its relationship with demographics and individual preferences. Journal of practice in Education, 5, 18-32.

[39] Onwuegbuzie, A.J(2004) Academic procrastination and statistics anxiety, Assessment evaluation Higher Edu,29.

[40] Al-Daghim, Freij and Al-Enzi, Muhammad (2003) The behavior of academic procrastination and its relationship to personality variables among students of the College of Education in Kuwait, Journal of Education, Mansoura University, 32

[41] Englander, F., Terregrossa, R. A., \& Wang, Z. (2010), Internet use among college students: tool or toy? Educational Review, 62(1), 85-96.

[42] Ozer. B.U. \& Ferrari, J, R (2011) Gender Orientation and academic procrastination Exploring Turkish high school students Individual Differences Research, 9 (1). 
[43] Lakshminarayan, N., Potdar, S. \&Reddy, D. (2013). Relationship between procrastination and academic performance among a group of undergraduate dental students in India. Journal of Dental Education, 77(4), 8 -24.

[44] Balkis, M \& Duru E., (2009). Behavalence of procrastination Behavior among Per service teachers and relationship with demographics and individual preferences -Journal of and practice in Education -5 18-32.

[45] Abdullah, Mahdi's dreams. (2013). Mindfulness among university students, Al-Ustad Magazine, Issue No. 10205, 205 Iraq.
[46] Albrecht, N.P. \& Cohen, M. (2012). Mindfully teaching in the classroom: Aliterature review. Australian Journal of teacher Education, 32, (12), 1.40.

[47] Hassed, C. (2012). Mindful learning: Why attention matters in education. International Journal of school \& Education Psychology, 4(1),52.60.

[48] Howell, A. J., \& Buro, K. (2011). Relations among mindfulness, achievement-related self-regulation, and achievement emotions. Journal of Happiness Studies: An Interdisciplinary Forum on Subjective Well-Being, 12(6), 1007-1022. https://doi.org/10.1007/s10902-010-9241-7 